ISSN: 0213-2060

DOI: https://doi.org/10.14201/shhme20183623960

\title{
DE CATEDRALES, ESCUELAS Y NIÑOS: EL EJEMPLO DEL TOLEDO BAJOMEDIEVAL*
}

\author{
About Cathedrals, Schools and Children. The Example of Late Medieval Toledo \\ María José LOP OTÍN \\ Depto. de Historia. Facultad de Humanidades de Toledo. Universidad de Castilla-La Mancha. Pza. de Padilla, \\ s/n.E-45071 TOLEDO. C. e.: MariaJose.Lop@uclm.es
}

Recibido: 2018-03-05

Revisado: 2018-03-21

Aceptado: 2018-10-29

RESUMEN: El presente trabajo se centra en la presencia de nińos en las catedrales medievales, mucho más frecuente de lo que en principio pudiera pensarse. Se sirve para ello del ejemplo del Toledo bajomedieval y analiza las cinco circunstancias en que esa presencia se hacía realidad: sus estudios en la escuela catedralicia; su colaboración en el desarrollo de las ceremonias litúrgicas; su estrecha participación en la actividad musical del templo; las fiestas en las que los nińos tenían un protagonismo especial; y la actividad asistencial que ofrece protección a los nińos abandonados.

Palabras clave: Catedrales; Escuelas; Niños; Toledo; Baja Edad Media.

ABSTRACT: This paper focuses on the presence of children in medieval cathedrals, which was much more common than previously thought. It takes the late medieval Toledo as an example and it analyzes the five circumstances in which this presence became a reality: their studies at the cathedral school; their collaboration in the development of liturgical

* Este trabajo se ha realizado en el marco del Proyecto de Investigación «La jerarquización urbana: villas y ciudades en Castilla (1400-1561)», financiado por el Ministerio de Economía y Competitividad (HARD2013-44014-P) y dirigido desde la Universidad Complutense de Madrid por la profesora María Asenjo González.

** Abreviaturas: ACT (Archivo Capitular de Toledo); Actas Cap. (Actas Capitulares); BCT (Biblioteca Capitular de Toledo); BN (Biblioteca Nacional); Ms. (Manuscrito). 
ceremonies; their close participation in the musical activity of the temple; the celebrations in which the children played a special role; and the assistance activity which offered protection to abandoned children.

Keywords: Cathedrals; Schools; Children; Toledo; Late Middle Ages.

SUMARIO: 0 Introducción. 1 Los niños y la escuela. 2 Los niños y la liturgia. 3 Los niños y la música. 4 Los niños y la fiesta. 5 Los «ninnos de la piedra». 6 Comentario final. 7 Referencias bibliográficas.

\section{INTRODUCCIÓN}

En septiembre de 2016 asistí en la catedral de Toledo a un concierto de los Niños Cantores de Viena. Mientras escuchaba sus espléndidas voces, me vinieron a la mente las muchas miradas infantiles y adolescentes que durante la Edad Media posarían sobre ella los nińos y jóvenes que, por razones distintas, estuvieron en contacto con este impresionante templo. En principio, el binomio infancia y catedrales puede parecernos poco factible, pero la realidad demuestra que ambos mundos tenían bastantes puntos de contacto, todos ellos vinculados a un cúmulo de actividades -educativas, litúrgicas, musicales, festivas, asistenciales- que aquí se aplicarán al marco toledano, aunque podrían ilustrarse con cualquier otro ejemplo.

Antes de comenzar habría que precisar el espectro temporal que abarcaría ese término «niños» del que hablaré en el trabajo y que arrancaría a los 7-8 años, edad aproximada a partir de la cual ingresaban en el templo. No sería, pues, la primera infancia, aquella en que los pequeños estaban vinculados al cuidado femenino -madres, nodrizas, criadas-, sino un segundo momento que marca «el umbral de un nuevo tramo de su existencia». Una etapa, en suma, en la que entra en juego el raciocinio y en la que nuestro protagonista, «además de iniciarse en los secretos de lo que más tarde constituiría su modo de vida, va adquiriendo un conocimiento del saber, de las letras y, por supuesto, de la doctrina cristiana ${ }^{1}$. Obvia decir que los niños a los que van dedicadas estas líneas son de sexo masculino, porque la presencia femenina no estaba en modo alguno contemplada en la vida catedralicia.

Es ya un lugar común señalar que en la Edad Media la infancia no era una etapa vital especialmente valorada y que el niño interesaba más en su versión adulta que en la realidad concreta de lo que significaba su edad. Como dijo Le Goff: «no hay niños, sino adultos pequeños» ${ }^{2}$. Ello no quiere decir que no fuera de gran importancia tener hijos, eran un bien necesario, ni que los padres no mostraran sentimientos hacia ellos. Nada más lejos. Lo que sucede es que los infantes interesaban más como proyecto de futuro,

1 García de Cortázar, José Ángel. «El ritmo del individuo: del nacimiento a la muerte». En Historia de España Menéndez Pidal. Madrid: Espasa-Calpe, 1994, vol. XVI, p. 276. Sobre las muchas propuestas y teorías que desde la Antigüedad compartimentaban la existencia humana, ver García Herrero, María del Carmen. «Las etapas de la vida». Medievalismo, 2004, vol. 13-14, pp. 29-48.

2 Le Goff, Jacques. La civilización del Occidente medieval. Barcelona: Paidos, 1999, p. 73. 
como embrión del hombre en que se llegarían a convertir. De hecho, se ven más defectos que virtudes en ellos y se les califica como seres inconstantes, inútiles, vagos, distraídos, despistados e incompletos ${ }^{3}$. Hay pues una "ambivalencia» en la percepción social de esa infancia, absolutamente necesaria, pero sin valores propios.

Apreciada o no, lo cierto es que era una etapa crucial para afirmar la personalidad y para la formación de la conciencia moral, pues marcaba el aprendizaje de aquello a lo que se estaba destinado a ser en el futuro, en condiciones normales, lo mismo que habían sido los padres. En efecto, el círculo familiar en el que había nacido y crecido el niño era determinante a la hora de marcar su desarrollo y profesión, pues es en este contexto donde comenzaba su educación. Trabajadores del campo, del sector artesanal o mercantil, futuros guerreros, el ambiente en el que vivían marcaba su devenir de forma inexorable y pocos podían sustraerse a ello. Eso sí, al margen del contexto concreto, en todos los casos se imponen y reproducen «los principios de obediencia, sumisión y respeto a la autoridad de los mayores, gratitud hacia los predecesores y utilidad $»^{4}$.

Ahora bien, junto a esta educación profesional que perpetuaba la tradición familiar, existía la posibilidad de alcanzar una formación especializada que solo una institución podía proporcionar. Era, obviamente, la Iglesia, que tras la crisis de la escuela antigua toma el relevo y pone en pie un programa escolar y educativo con la finalidad de formar sus cuadros clericales y asegurar el relevo generacional de los ministros del culto. A los eclesiásticos se les exige ser litterati, al menos en unos mínimos, pues la responsabilidad que caía sobre sus hombros era importante de cara a adoctrinar a los fieles y acercarles los distintos servicios religiosos. Indudablemente, la Iglesia más allá de trasmitir unos conocimientos tendrá un papel fundamental en la definición de la personalidad de estos jóvenes estudiantes al tiempo que podía asentar un código de valores, justificar el orden social y sancionar la correcta cosmovisión ${ }^{5}$.

Parroquias, monasterios y catedrales desarrollarán así diferentes propuestas educativas que a muchos jóvenes les proporcionaron un aceptable medio de vida. Aquí nos ocuparemos solo de las últimas, que se implican pronto en ese papel docente y ya en la Alta Edad Media vemos florecer diversas escuelas episcopales, si bien su desarrollo no está del todo generalizado, pues dependerá mucho del interés de los obispos y del grado de implicación con la actividad cultural de su diócesis. Será a partir del siglo XI cuando el peso de las catedrales sea mayor, entre otros factores, por el papel que les otorga la normativa conciliar fruto de la reforma que se impulsa desde el papado y que tiene entre sus objetivos promover la existencia de un clero bien preparado intelectualmente, formado en las cuestiones de fe y capaz de trasmitirlas a sus feligreses. Entre esas disposiciones destacan la del concilio de Roma (1078), en la que Gregorio VII señaló la obligación que tenían los obispos de enseñar Artes Liberales en sus iglesias; la del Concilio III de Letrán (1179), que declara a las escuelas obligatorias en todas las catedrales bajo el control del obispo,

3 García Herrero, María del Carmen. «Elementos para una historia de la infancia y la juventud a fines de la Edad Media». En La vida cotidiana en la Edad Media. Logrońo: Instituto de Estudios Riojanos, 2011, pp. 223-252.

4 Ibidem, p. 240.

5 Sabaté, Flocel. «La formació de la personalitat a l'Edat Mitjana». En SABatÉ, Flocel (ed.). La formació de la personalitat a l'Edat Mitjana. Lleida: Pagès editors, 2016, pp. 9-22. 
representado habitualmente por el maestrescuela; y la del Concilio IV de Letrán (1215), que además de confirmar las medidas anteriores añade que en las iglesias metropolitanas, además, habrá un teólogo que enseñe a los sacerdotes la Sagrada Escritura ${ }^{6}$.

Como he dicho al principio, una sola catedral, la de Toledo, será la protagonista de las siguientes líneas, en las que intentaré analizar las diversas circunstancias en que se concretaba la presencia de niños en el templo. Me centraré en la etapa bajomedieval, en la que la institución estaba en plena madurez y era el auténtico eje de la vida religiosa de la ciudad. Es en ese momento cuando tiene completada su composición y estructura interna, representada por 14 dignidades, 40 canónigos prebendados o mansionarios, 50 racioneros, 20 canónigos extravagantes, más de 100 capellanes entre los del coro, de la greda y las capillas, y 40 clerizones que se educaban en la escuela catedralicia. Ello convertía a la corporación toledana en una de las más numerosas de los reinos hispanos y, sin duda, hacía sentir a los habitantes de la ciudad de Toledo el enorme poder de una catedral que era mucho más que un gran y bello edificio; era también el punto de partida de numerosas iniciativas religiosas, asistenciales y culturales, que tenían un evidente impacto en su entorno más cercano ${ }^{7}$.

La posibilidad de realizar este estudio parte de la rica documentación custodiada en el Archivo Capitular, especialmente la contenida en ceremoniales, actas de las reuniones del cabildo y en los estatutos que afrontan el tema de manera directa. Destaca en ese sentido la recopilación de la normativa capitular vigente que en 1357 hizo el arzobispo Blas Fernández de Toledo ${ }^{8}$. En ella se reúnen algunas constituciones que, con el título de offiçio scolastici, de offiçio magistri claustralis, de offiçio puerorum vel infantium, de scolaribus, precisan muy bien algunos aspectos relativos a la presencia de niños en la catedral y al papel que desarrollaban. Habrá ocasión de mencionarlas con detalle a lo largo del artículo, que he distribuido en 5 apartados: niños y escuela; niños y liturgia; niños y música; niños y fiesta; niños de la piedra.

\section{LOS NIÑOS Y LA ESCUELA}

Sin duda, el motivo principal para que niños y jóvenes recorrieran los distintos espacios de las catedrales medievales era el de participar de las enseñanzas que de forma gratuita ofrecían sus escuelas. La de Toledo, como luego veremos, estaba ya constituida

6 Guijarro González, Susana. Maestros, escuelas y libros: el universo cultural de las catedrales en la Castilla medieval. Madrid: Dykinson, $2004 \mathrm{y}$ «El saber de los claustros: las escuelas monásticas y catedralicias en la Edad Media». Arbor: ciencia, pensamiento y cultura, 2008, vol. 731, pp. 443-455; Martín Prieto, Pablo. La cultura en el Occidente medieval. Una sintesis histórica. Madrid: La Ergástula, 2013; PAuL, Jacques. Historia intelectual del Occidente medieval. Madrid: Cátedra, 2003; Sánchez Prieto, Ana Belén. «Dónde aprender a leer y escribir en el año mil». Anuario de Estudios Medievales, 2010, vol. 40, n. ${ }^{\circ}$ 1, pp. 3-34.

7 Lop OTín, María José. El Cabildo catedralicio de Toledo en el siglo XV: Aspectos institucionales y sociológicos. Madrid: Fundación Ramón Areces, 2003.

8 Se trata de las Constituciones Ecclesie Toletane facte per Reverendissimum in Christo Patrem et Dominum Blasium Archiepiscopum Toletanum Hyspaniarum Primatem, publicadas el 13 de septiembre de 1357. El texto lo conocemos a través de varias copias, una de ellas se conserva en BCT, Ms. 23-17, fols. 1r-26v. Aquí citaré la copia realizada en 1595 y conservada en BN, Ms. 6260, fols. 1r-23v. 
en el siglo XII, antes incluso de la citada medida del Concilio III de Letrán. El cabildo de la sede primada se preocupó desde bien pronto por la adecuada formación de sus miembros, de ahí que exigiera a quienes optaran a ocupar una prebenda en la catedral que ostentaran al menos dos de estos títulos, bene cantandi, bene legendi et bene construendi ${ }^{9}$, en clara alusión a la necesidad de que tuvieran una preparación suficiente para desempeñar las tareas litúrgicas que se desarrollaban en el templo y que les obligaban a leer y comprender los textos sagrados, a cantar en las diferentes celebraciones y a ser capaces de expresarse con elocuencia a la hora de predicar los correspondientes sermones y homilías.

Esa preparación no podía improvisarse, comenzaba desde abajo, siendo sus destinatarios un grupo de niños y jóvenes a los que la documentación toledana denomina clerizones, «moços», «clericelli» o «nińos del coro» y que, en número de 40, se educaban en la escuela catedralicia ${ }^{10}$. Para ser admitidos, debían contar entre 8-10 años y pasar unas pruebas de lectura y canto ante una de las más importantes dignidades del cabildo, el maestrescuela, tras lo cual eran ordenados de tonsura en una suerte de ceremonia de iniciación clerical y recibían un beneficio eclesiástico durante el tiempo que estuvieran vinculados a la catedral. También se les remuneraba con una cantidad diaria para fomentar su presencia en las horas y servicios litúrgicos, a los que me referiré más tarde. Beneficio y distribuciones diarias pretendían ayudar a su manutención y alojamiento que se hacía en régimen externo fuera del templo, y que corría totalmente de su cuenta. Si con ello no tenían suficiente, debía socorrerlos su familia o aquellos que los hubieran recomendado para entrar en el templo, a cuyo cuidado quedaría la provisión de lo necesario para cubrir las necesidades de sus patrocinados. Muchas eran las personas que querían que sus hijos y familiares ingresaran como clerizones, dadas sus posibilidades de promoción en la carrera eclesiástica, donde, si mostraban aptitudes, podían alcanzar las más altas prebendas en la propia Toledo o en otras catedrales. Si por el contrario querían reintegrarse en la vida laica, contaban, al menos, con una sólida formación que les permitía diversas salidas profesionales. Además, aquellos que, como luego veremos, destacaban por su buena voz y capacidad para el canto podían iniciar unos estudios musicales especializados ${ }^{11}$.

A pesar de ser el escalón inferior en el conjunto de beneficiados de la catedral, su corta edad, lo decisivo de orientarles en la forma correcta y, por qué no, sus frecuentes travesuras, obligaron a arzobispos y cabildo a ocuparse muy estrechamente de regular su paso por el templo. El encargado de dirigir toda esa actividad educativa era el maestrescuela, dignidad cuya presencia en Toledo es anterior a la medida del citado Concilio III de Letrán (1179), que obliga a todas las catedrales a contar con un maestro de gramática que enseñara gratuitamente a los clérigos de las iglesias y a los niños pobres

9 BN, Ms. 6260, fol. 1v.

10 El número era mayor, porque también acudían otros nińos externos, no clerizones, a los que se daba enseñanza gratuita, sin derecho eclesiástico alguno. Entre unos y otros podían llegar al centenar.

11 El ambiente que rodeaba a este grupo de estudiantes está muy bien recogido por GonzáLVEz Ruiz, Ramón. «La Escuela catedralicia». En GonzÁlvez Ruiz, Ramón (coord.). La Catedral Primada de Toledo. Dieciocho siglos de historia. Burgos: Promecal Publicaciones, 2010, pp. 518-525, y por Lop OTín, María José. «La Catedral de Toledo, ente generador de cultura a fines de la Edad Media». En Boucheron, Patrick y Ruiz Gómez, Francisco (coords.). Modelos culturales y normas sociales al final de la Edad Media. Cuenca: Casa de Velázquez-Universidad de Castilla-La Mancha, 2009, pp. 357-385. 
que lo desearan a fin de mejorar el nivel cultural del clero del momento. En Toledo aparece mencionado ya en la constitución de don Cerebruno de $1174^{12}$ y, aún antes, dada la necesidad de instruir a los clérigos francos que constituyeron el primer cabildo desde finales del siglo XI y comienzos del XII ${ }^{13}$. El magister scholarum era el director de la escuela o escuelas catedralicias en los diferentes niveles de instrucción que se impartían en la misma y a su cargo estaba velar por todo lo que tuviera relación con esta relevante actividad educativa de la catedral. Su función no era la enseñanza personal, sino la de proveer los maestros más preparados en gramática y dialéctica, cuidar de que cobraran su salario, vigilar los horarios e inspeccionar todo lo relativo a la institución escolar. Debía permitir que aquel que lo quisiere, aunque no perteneciese a la catedral, pudiese recibir estas enseñanzas, y de forma gratuita si no tenía posibilidades económicas ${ }^{14}$.

Los clerizones eran instruidos en varias materias (gramática, cómputo, Sagradas Escrituras, derecho o música) que, obviamente se organizaban en diversos niveles de enseñanza, que iban desde el más bajo grado de los niños o infantes a la formación clerical superior. El primer nivel de las enseñanzas impartidas en la catedral lo constituye la Escuela de Gramática, que no hay que considerar una escuela de primeras letras, pues, como dije antes, los escolares debían saber leer y escribir cuando accedían a ella en torno a los 8-10 ańos. Sería más bien una escuela de enseñanzas medias en las que en un primer nivel se impartía gramática latina, canto llano y cálculo elemental, así como un conocimiento de las ceremonias litúrgicas desarrolladas en la Iglesia. A partir de ahí, los alumnos cursaban de forma más completa las materias que componían el trivium -gramática, retórica y dialéctica- hasta completar una sólida formación literaria que preparaba a buenos predicadores. Igualmente podían impartirse conocimientos generales de las ciencias del quadrivium -geometría, aritmética, astronomía y música-, aunque es más difícil determinar en qué grado ${ }^{15}$. Estas siete Artes Liberales, fijadas ya por Marciano Capella en el siglo v como propias de la formación escolar, se convirtieron en el puntal de las enseñanzas durante toda la Edad Media, siendo consideradas el paso previo a los estudios más especializados de Teología.

La escuela ocupaba varios locales, entre ellos uno en el claustro bajo, lugar de esparcimiento de los escolares, que daba acceso directo a otro importante espacio ligado a la actividad cultural, la Biblioteca, cuyos fondos eran necesarios para el desarrollo de los estudios. Esta se constituye oficialmente a fines del siglo xIv, cuando en tiempos del arzobispo Pedro Tenorio los libros se independizan del Tesoro al que hasta ahora pertenecían

12 ACT, Z.1.G.1.3. El texto menciona a un Johannes toletane ecclesie magister scholarum.

13 Lo que sí está con seguridad documentado desde 1115 es el cargo de grammaticus, no identificable con el maestrescuela, pero, sin duda, cumpliendo ya en fecha tan temprana unas funciones en materia cultural que serían continuas a lo largo de todo el periodo medieval.

14 Detalla de forma muy precisa sus funciones una constitución recogida en BN, Ms. 6260, fol. 12r.

15 Bartolomé Martínez, Bernabé. «Escuelas de Gramática». En Diccionario de Historia Eclesiástica de España. Madrid: Consejo Superior de Investigaciones Científicas, 1987, Supl. I, pp. 290-291; Guijarro GonZÁLEZ, Susana. «Las escuelas y la formación del clero de las catedrales en las diócesis castellano-leonesas». En La Enseñanza en la Edad Media. Logrońo: Instituto de Estudios Riojanos, 2000, pp. 61-96. Interesantes reflexiones también en la obra colectiva Historia de la acción educadora de la Iglesia en España. I. Edades Antigua, Media y Moderna. Madrid: Biblioteca de Autores Cristianos, 1995. 
y se establecen en un local accesible desde el claustro, en el que se construirían armarios, mesas, atriles y bancos, y, además, a fin de mantener unos fondos estables y de poder llevar un control más rígido del sistema de préstamos, se nombraría un "guarda de la librería», se elaborarían índices y se sujetarían los volúmenes con cadenas en un intento de evitar que pudieran sacarse indiscriminadamente. Gracias a un inventario de este recinto realizado en 1455, el primero tras la reorganización de Tenorio, sabemos que albergaría cerca de 400 libros. Una parte de ellos sería de utilidad para el estudio de las artes del trivium (salterios, diccionarios, obras de corte enciclopédico), y lecturas muy diversas, a las que se suman también 16 libros de ciencias, representativos del quadrivium ${ }^{16}$.

Superada esta etapa adolescente y en torno a los 16-18 años, aquellos clerizones que mostraran aptitudes y desearan seguir la carrera eclesiástica en su más alto grado, pasaban al nivel superior de las enseńanzas que se impartían en Toledo, el de la Escuela de Teología. El estudio de las Sagradas Escrituras era fundamental para completar la formación del clero y de ahí que desde el Concilio IV de Letrán se exija la presencia de un maestro de esta materia en las catedrales más importantes, las metropolitanas, entre las que, sin duda, se encuentra la sede toledana. Aquí debió existir esta figura desde el principio, pues, aunque no hay constancia escrita de ello, la presencia en la Biblioteca Capitular ya en el siglo XII de algunos manuscritos y textos en los que se glosan algunos manuales de Teología así lo atestigua.

No obstante, cuando podemos constatar más claramente que estas enseñanzas se impartieron en la catedral a cargo del cabildo es en el siglo xv. Prueba de ello es que en la misma se aplicó con rapidez la bula de Sixto IV, del 27 de abril de 1476, en la que, a fin de evitar la designación de personas poco ilustradas, se ordenaba a todos estos templos la provisión de dos canonjías en licenciados o doctores en Teología y Derecho, las canonjías magistral y doctoral ${ }^{17}$. La primera de ellas recayó durante un tiempo en Pedro Jiménez de Préjamo, pero tras su elevación al obispado de Badajoz en 1486 no debió ser fácil proveerla y de ahí que el cabildo decidiera encomendar la enseñanza de la Teología y la cátedra que sobre tal materia se había fundado en la catedral a prestigiosos miembros de las órdenes religiosas implantadas en Toledo. Esta fue práctica habitual entre los cabildos, que, si no podían encontrar a otras personas lo suficientemente preparadas para el puesto, se servían temporalmente de estos frailes formados en prestigiosas universidades. Las actas capitulares dejan constancia del nombramiento para ocupar esta cátedra, en 1490, del maestro fray Hernando de Espina, «frayle de la Orden de San Francisco de la claustral desta çibdad» y de fray Martín de Vitoria en $1493^{18}$. Las principales enseñanzas que se imparten en esta Escuela de Teología serían Sagradas Escrituras, Cánones y Liturgia, tal como se refleja en la Biblioteca catedralicia, donde un abundante número de volúmenes, en torno a los 200, son de materia religiosa o eclesiástica en sentido amplio, mientras que 105 conforman un importante fondo de libros jurídicos tanto de derecho canónico como civil.

16 Lop Otín, El Cabildo catedralicio de Toledo en el siglo XV, pp. 393-404.

17 ACT, A.12.A.2.4. No es un mandato exclusivo para Toledo, sino que debe ser aplicado a todas las iglesias de Castilla y León.

18 ACT, Actas Cap. II, fol. 2v (1490, junio, 28) y fol. 54v (1493, agosto, 8). 
DE CATEDRALES, ESCUELAS Y NIÑOS: EL EJEMPLO DEL TOLEDO BAJOMEDIEVAL MARÍA JOSÉ LOP OTÍN

46

A fines del siglo la preocupación por la formación de estos clerizones, en sus niveles superiores, propició que el maestrescuela y canónigo, Francisco Álvarez Zapata, doctor in utroque iure, de ascendencia conversa y uno de los más ilustres toledanos de la época, decidiera fundar un colegio, que pondría bajo la advocación de Santa Catalina. Para ello pidió al cabildo una casa situada en la parroquia de San Andrés en la que atender más específicamente a un grupo de ellos y solicitó del papa Inocencio VIII el reconocimiento de su fundación, algo que se plasmó en la bula Etsi nos, otorgada el 7 de mayo de 1485, tras la que empieza a funcionar esta institución educativa. Las constituciones dadas por el fundador establecieron el doble carácter de residencia para 30 clerizones pobres, en la que recibirían manutención y todo tipo de asistencia material, y, por otro, el de centro de formación y preparación para alcanzar el sacerdocio. Los colegiales, para ser admitidos, debían tener entre 16 y 20 años; ser naturales de la diócesis o al menos de la provincia eclesiástica; saber leer, tener buena voz y haber cursado un año de gramática; contar con escasas posibilidades económicas; mostrar vocación por el estado eclesiástico; y ser honestos y de buenas costumbres. Durante este tiempo de estudio y preparación debían servir en el coro de la catedral y estar presentes en las horas litúrgicas. Tres cargos -rector, canciller y capellán- se encargarían del funcionamiento del colegio, siempre bajo la obediencia del maestrescuela ${ }^{19}$. El Colegio sería el germen de la Universidad que la ciudad vería florecer a partir del siglo XVI, en concreto en 1529, cuando se constituye la «Real y Pontificia» Universidad de Toledo ${ }^{20}$.

La nueva etapa abierta en la vida cultural y educativa de la ciudad con la transformación del Colegio en Universidad hizo que tomara el relevo en la formación de los clerizones una nueva institución. Se trata del Colegio de Nuestra Señora de los Infantes, fundado en 1552 por el cardenal Juan Martínez Silíceo para atender a 40 nińos entre los 8 y los 12 años, y cuyas constituciones otorgadas cinco años después lo situaron bajo la órbita del cabildo, que era su administrador ${ }^{21}$. Su continuidad en Toledo se ha prolongado hasta nuestros días, en que desde una nueva ubicación ofrece todos los niveles educativos y es uno de los centros de enseñanza de referencia en la ciudad. Por su parte, el local original que ocupaba, muy cerca del templo primado y poseedor de una magnífica portada, ha sido recientemente remodelado para instalar el Museo de Tapices y Textiles de la Catedral.

19 Canabal Rodríguez, Laura. «Conversos toledanos en un espacio de poder, la catedral primada. Don Francisco Álvarez de Toledo, canónigo y mecenas (ss. Xv y xvi)». Espacio, Tiempo y Forma. Serie IV, Historia Moderna, 2011, vol. 24, pp. 13-32; Gómez Sánchez, Florentino. "El Colegio de Santa Catalina y la Universidad de Toledo». Iluminar, 1988, vol. I, pp. 61-78; Vizuete Mendoza, José Carlos. «La Universidad y los Colegios de Santa Catalina y San Bernardino». En Gonzálvez Ruiz (coord.), La Catedral Primada de Toledo, pp. 534-541.

${ }_{20}$ Lorente Toledo, Luis. La Real y Pontificia Universidad de Toledo. Siglos XVI-XIX. Toledo: Universidad de Castilla-La Mancha, 1999; Vizuete Mendoza, José Carlos. «Universidad de Toledo: historiografía, fuentes documentales y líneas de investigación». En Universidades hispánicas: modelos territoriales en la Edad Moderna. Salamanca: Universidad de Salamanca, 2007, vol. 2, pp. 65-106, y Los antiguos colegios-universidad de Toledo y Almagro. Cuenca: Universidad de Castilla-La Mancha, 2010.

${ }_{21}$ López Gómez, Juan Estanislao. El Colegio de Infantes de Toledo en la Edad Moderna, 1552-1808. Toledo: Grupo Díaz Redondo, 2007. 
DE CATEDRALES, ESCUELAS Y NIÑOS: EL EJEMPLO DEL TOLEDO BAJOMEDIEVAL

MARÍA JOSÉ LOP OTÍN

La actividad litúrgica y cultual era la principal ocupación de todo cabildo catedralicio. Esto que, sin duda, vale para cualquier catedral europea e hispana, es bien evidente en el caso toledano, pues, por su condición de sede primada, sus responsables se sienten obligados a mostrar su superioridad y a señalar el camino al resto de las iglesias «porque de ella como matriz tomen las otras enxemplo», según recuerda el arzobispo Alonso Carrillo en el sínodo alcalaíno de $1480^{22}$. Unos años antes, un estatuto capitular insiste en «la exçelençia y magnifiçençia», que debe mostrar en todo momento este templo, a fin de que sea «luz y espejo que todas las otras yglesias an de mirar y aver acatamiento» ${ }^{23}$. Por ello desde el siglo XIII son numerosos los estatutos y ordenamientos que regulan hasta el más mínimo detalle del ceremonial a desplegar y de las tareas que para su desarrollo debía completar la amplia nómina de personas que se movían en torno al templo.

En el servicio litúrgico del templo estaban implicados todos los colectivos clericales y laicos que confluían en el templo, pues las necesidades litúrgicas exigían la colaboración de todos y cada uno de los sectores que componían la compleja estructura catedralicia. Nadie, empezando por el propio arzobispo cuando estaba en la ciudad y terminando por el último sirviente o auxiliar, estaba excusado de ayudar en una u otra forma a sostener y hacer posible la gran obra catedralicia, poniendo de manifiesto su grandeza. No se puede ignorar que el clero capitular estaba profundamente jerarquizado -lugares asignados en el coro, en las procesiones, indumentaria diferente-, pero eso no impedía que todos, independientemente de su función a desempeñar, tuvieran como común objetivo y empresa, en cierto modo unificadora, el contribuir a ensalzar el opus Dei. Era el papel que les correspondía cumplir como oratores y miembros del sector de la sociedad que tenía como signo distintivo rezar por la salvación del resto.

Entre la numerosa oferta litúrgica que presentaba la catedral primada y que tuve ocasión de analizar en otro lugar ${ }^{24}$, sobresalía, sin duda, el servicio del coro, dado que era la tarea que llenaba más tiempo en la vida del personal vinculado al templo, siendo, además, el elemento que organizaba su horario. El rezo coral se distribuía en la catedral entre las tres horas mayores de maitines, misa mayor y vísperas, y las cinco menores de prima, tercia, sexta, nona y completas ${ }^{25}$. La distinción entre horas mayores y menores estribaba en el espacio temporal que abarcaban, el tipo de oficio que se decía y la retribución económica que se entregaba por asistir a ellas, es decir, las distribuciones cotidianas. En 1477 se determina dar a cada una de las horas menores, 2 mrs a los canónigos y 1 a los racioneros, y en misa mayor y vísperas 3 al canónigo y al racionero la mitad, 3 blancas ${ }^{26}$.

22 García y García, Antonio (dir.). Synodicon Hispanum. X. Cuenca y Toledo. Madrid: Biblioteca de Autores Cristianos, 2011, p. 631.

23 BN, Ms. 6260, fol. 35v.

24 Lop OTín, El Cabildo catedralicio de Toledo en el siglo XV, pp. 250-286, y «El esplendor litúrgico de la catedral primada de Toledo durante la Edad Media». Medievalia, 2014, vol. 17, pp. 185-213.

25 Con relación al tradicional horario dispuesto en la regla benedictina se han suprimido los laudes y se ha incorporado la misa mayor, después de tercia.

26 ACT, Actas Cap. I, fol. 97r-v (1477, septiembre, 30). 
En el servicio del coro era tanta la necesidad de personal que, no solo cumplían un papel destacado canónigos, racioneros y capellanes, sino también el sector que ocupaba el escalón más bajo entre la clerecía del templo, esto es, el de nuestros clerizones. Ellos sumaban a las lecciones teóricas que reciben en la escuela la "práctica» litúrgica como auxiliares y servidores del coro, pues tenían encomendadas tareas concretas en las diferentes celebraciones. Entre las obligaciones de estos jóvenes estaba cantar la misa diaria de Nuestra Señora o «de la aurora» en la capilla de San Ildefonso, tal como quedó ya dispuesto en el siglo $\mathrm{XIII}^{27}$, y atender al servicio del coro, alternándose en dos turnos semanales: la semana de lectoría, en que cantaban las lecciones, y la semana de colectoría, en que cantaban las colectas. También les correspondía decir las lecciones y responsos en los oficios de las horas, diurnos y nocturnos, pernoctando en el templo en este último caso, así como llevar el cirio pascual en las procesiones ${ }^{28}$. Su presencia era especialmente requerida en el oficio nocturno de maitines, ya que la oscuridad de la noche y el frío del templo, unido a que eran los oficios más largos, frenaban considerablemente la asistencia de los beneficiados. Por ello las compensaciones por asistir a los mismos eran considerablemente mayores que al resto de las horas ${ }^{29}$ y por eso también la participación de los clerizones era tan importante. También ellos percibían las correspondientes distribuciones por la asistencia a las horas canónicas, tal como se fijó en el siglo xiv, cuando el arzobispo Blas Fernández les asignó 4 denarios por participar en los oficios de prima, 3 a los de nona y 6 a la misa; además, las semanas de lectoría y colectoría les eran retribuidas con $3 \mathrm{mrs}$.

Este adiestramiento en el oficio religioso era especialmente vigilado por otra importante dignidad capitular, el chantre o capiscol, que debía estar muy atento durante las celebraciones a los posibles fallos para corregirles y enseñarles en la forma debida. El cargo existe desde finales del siglo XI, primeramente bajo la denominación de precentor, y es uno de los pocos que aparece explícitamente citado en la documentación conservada sobre la primera época del cabildo. Era la máxima autoridad en materia litúrgica y en lo relacionado con las celebraciones corales, las misas y demás servicios de altar que se realizaban en la catedral. Además de designar semanalmente a los canónigos, racioneros y capellanes que se harían cargo de los cantos, salmos o lecturas, buena parte de su tiempo lo dedicaba a los clerizones. De entrada, los examinaba para ver sus aptitudes en lectura y canto y, dado que estaban en un proceso de formación, debía inspeccionar cuidadosamente el tiempo que pasaban en el coro ${ }^{30}$.

Estas tareas corales no siempre serían realizadas con el respeto debido y, a tenor de lo que dicen los estatutos desde el siglo XIII, las risas, murmullos y disputas entre estos jóvenes serían frecuentes, pues dada su edad, era difícil contener sus manifestaciones. Ello, no solo suponía una falta de respeto a la actividad que allí se desarrollaba, sino que distraía a los otros beneficiados y les impedía estar atentos a hacer las pausas en los cantos, descubrirse la cabeza o a hacer sus oraciones en el momento correcto. Un ritual

27 ACT, I.6.C.1.1.

28 Es una vez más don Blas Fernández en las constituciones dadas en 1357 quien regula muchos aspectos de este colectivo al dedicarles el estatuto De offçio puerorum vel infantium: BN, Ms. 6260, fol. 14r-v.

29 En diciembre de 1471 se acordó otorgar al canónigo $14 \mathrm{mrs}$, al racionero 7 y al capellán 4; cifras sensiblemente superiores a las de las demás horas: ACT, Actas Cap. I, fol. 42r.

30 BN, Ms. 6260, fol. 10r. 
tan complejo como el catedralicio no podía seguirse sin un mínimo de silencio, por lo que las recomendaciones de los estatutos son continuas para que se evite toda murmuración y comentario, hasta el punto de determinar que no se inicien los oficios hasta que el silencio sea total. El desorden que ello provocaba se incrementaba si iba acompañado de otra frecuente falta, el abandono de su asiento por algunos, que saltaban de un sitio a otro indiscriminadamente, algo prohibido «aunque aya para ello urgente necesidad $»^{31}$. Por eso era función del chantre velar por la honestidad del coro, acabando con estos comportamientos impropios, y una de las constituciones del estatuto de Blas Fernández le recuerda su obligación de emmendare cleriçellorum chori insolentias et quecumque allia negoçia, questiones et lites que inter eosdem emerserint prout sibi videbit punire et termina$r e^{32}$. Ese castigo se concretaba en la pérdida de la ración de ese día y de las distribuciones de la hora correspondiente, si no rectificaban. Igualmente debía procurar que los jóvenes llevaran bien hecha la corona o tonsura y que tuvieran una «buena compostura exterior». En relación a esta, una vez admitida su presencia en el coro por el arzobispo y el cabildo, aquel de los beneficiados que lo hubiera patrocinado estaba obligado a costearle la capa, la sobrepelliz y el calzado con el que debería atender sus obligaciones corales, si su ración no le alcanzase para ello.

\section{Los NIÑOS Y LA MÚSICA}

La música constituía una de las enseñanzas más especializada que se impartía en la catedral -era una de las cuatro disciplinas que componían el quadrivium-, habida cuenta de que las distintas fiestas y solemnidades del calendario litúrgico se adornaban con un buen número de composiciones tanto de canto llano como polifónico. Ello exigía la participación de músicos, cantores e instrumentistas, que se hace cada vez más numerosa y decisiva conforme nos acercamos al Renacimiento. En efecto, el gran esplendor musical de la liturgia toledana se produjo en el siglo XVI, en el que no se escatimaron esfuerzos para buscar compositores y contratar cantores e instrumentistas de la mayor calidad con el fin de que «las divinas alabanzas del culto pudieran resonar a través del templo con una magnificencia que igualaría, e incluso superaría, a sus modelos homónimos de las artes plásticas ${ }^{33}$. Esta decidida apuesta por la polifonía, constatada en la catedral desde la etapa medieval, hizo que el estudio de la música se individualizara del conjunto de enseñanzas que se impartían en la misma y tuviera sus propios maestros, alumnos y métodos.

En Toledo había dos niveles en el conocimiento de una enseñanza tan especializada como la música. En un nivel elemental, que comprendía el canto llano o de melodía,

31 BCT, Ms. 42-29, fol. 195r.

32 BN, Ms. 6260, fol. 10r.

33 Noone, Michael. «La música medieval y renacentista». En GonzÁlvez Ruiz (coord.), La Catedral Primada de Toledo, p. 332. Entre los trabajos que se han ocupado de esta faceta destacan: Reynaud, François. La polyphonie tolédane et son milieu. Des premiers témoignages aux environs de 1600. Paris-Turnhout: Brepols, 1996; Les enfants de choeur de Tolède à la Renaissance. Les clerizones de la cathédrale et le Colegio de los Infantes. Turnhout: Brepols, 2002; Esteve Roldán, Eva. Mecenazgo, Reforma y música en la Catedral de Toledo (1523-1545). Tesis doctoral leída en la Universidad Complutense. Madrid, 2015. 
eran todos los escolares los que estaban implicados, de ahí que en la misma escuela de Gramática se impartieran unas nociones generales comunes a todos los alumnos. Estas enseñanzas estaban a cargo del maestro claustral o claustrero, racionero encargado de instruirles in canto et usu ecclesiae y de corregir sus fallos hasta conseguir que alcanzaran el nivel adecuado ${ }^{34}$. En 1476 el claustrero recibió una importante ordenación del cabildo, en la que se le denomina "oficial de los ninnos de les mostrar la melodía» y con la que se intenta frenar lo que debía ser una actuación poco diligente de sus responsables. Para ello le advierten que será objeto de visitas por el partidor encargado de realizar las distribuciones a las horas y «la hora que no fallase al claustrero en la dicha escuela con los moços mostrándolos e instruyéndolos o estoviese en el coro, que le quitase la tal hora e no gela esemiesen $^{35}$. La rotundidad con que se expresan los capitulares da fe del descontento que sentían ante la actitud de estos oficiales.

El claustrero debía conocer muy bien a los niños y procurarles una enseñanza personalizada «según cada uno incumbía e su capaçidat bastante porque la eglesia se sirviese dellos e ellos aprendiesen e saliesen buenos clérigos ${ }^{36}$. Este cargo se vinculaba a una de las cincuenta raciones instituidas en la catedral, a fin de que la importante labor que llevan a cabo educando a los jóvenes in divinis oficiis et praesertim cantu seu musica de melodia no se viera afectada. Así lo recoge la bula otorgada por Nicolás V en 1448 en respuesta a una demanda del deán y cabildo toledanos, preocupados por la negligencia con que se cumplían estas importantes tareas por no contar con una remuneración adecuada. Su preparación le permitió ocupar el puesto de organista desde que este instrumento se fue introduciendo a lo largo del siglo XIv para acompañar las voces en los oficios ${ }^{37}$. Luego, cuando el órgano empezó a requerir conocimientos cada vez más especializados, su cuidado quedó en manos de expertos profesionales contratados por el cabildo.

Un nivel superior era el de la educación especializada que recibían los seises, niños expertos en polifonía. Ciertamente, conforme el canto polifónico se impone y la música adquiere la relevancia señalada en los servicios litúrgicos de la catedral, se crea una formación musical que insiste en el aprendizaje del canto de órgano o canto polifónico, el contrapunto y la composición. Los destinatarios de esta formación musical especializada eran una parte de los clerizones que, por sus adecuadas aptitudes para el canto, se individualizaron del conjunto y pasaron a constituir el grupo de los «moços del coro», «niños del coro», "cleriçones de canto de órgano» o «seises», este último término en atención a su número que ya en el siglo $\mathrm{XV}$ se fija en $\operatorname{seis}^{38}$. Este pequeńo grupo de nińos cantores de entre 6 y 13 años hacía vida en común cerca de la catedral o incluso en algún recinto del claustro, diferenciándose así de los demás clerizones. La necesidad de velar por sus voces y de «mimar» su aprendizaje hizo que este fuera encomendado a un cargo específico que, además de enseñarles el canto, vivía con ellos y se preocupaba de su manutención.

34 BN, Ms. 6260, fol. 12v.

35 ACT, Actas Cap. I, fol. 88r (1476, agosto, 16).

36 Ibidem.

37 El estatuto de don Blas de 1357 recoge perfectamente la expresión, si ad id erudictus et sufficiens existat pulsatio horganorum.

38 A mediados del xiv, como consta en el testamento del arzobispo Blas Fernández de Toledo, su número era de cuatro. 
Recibía diversos nombres en las fuentes - «maestro de los niños», «maestro de la música» $\mathrm{o}$ «maestro de los seises»-, que no hay que confundir con el citado claustrero, que enseñaba canto de melodía, es decir, no polifónico, a todo el conjunto de los clerizones, no solo a los seises.

Era imprescindible para pertenecer a este selecto grupo cumplir algunos requisitos de idoneidad: estar en posesión de una buena voz; saber leer y escribir; ser aptos para leer la música y memorizarla; proceder de una familia de intachables costumbres; y gozar de buena salud ${ }^{39}$. Las posibilidades de promoción que estos niños tenían de seguir la carrera eclesiástica o de ejercer como cantores profesionales eran grandes y de ahí el interés de muchos padres por lograr el ingreso de sus hijos, quienes, en función de la edad que tenían al entrar, permanecían en el templo entre tres y nueve años. A los padres no se les reclama ninguna situación social o económica determinada para la aceptación de sus hijos ${ }^{40}$. La única obligación y compromiso que les exige el cabildo era la de «no los quitar a los ninnos del dicho serviçio", so pena de una severa multa y, en el caso de que los niños se escaparan, circunstancia que no debía ser infrecuente a juzgar por la reiteración con que trata de evitarse, debían hacerles volver «a su costa e mysyón» hasta completar su formación.

\section{LOS NIÑOS Y LA FIESTA}

La presencia de niños y adolescentes en las diversas fiestas y ceremonias medievales, mayoritariamente del medio urbano, no era en modo alguno excepcional y así lo manifiestan numerosos testimonios escritos y figurados. Su función en ellas era muy variada: «la inmediata de integración política, también de continuidad social, la simbólica de pureza y bondad, y la propiciatoria de movilización de fuerzas benéficas para la comunidad $\aleph^{41}$. Las catedrales ofrecían un inmejorable escenario para que ese grupo infantil y juvenil explotara esa vertiente festiva, especialmente en el tiempo litúrgico de la Navidad, un tiempo de alegría espiritual que conmemora la venida al mundo de un niño y es por ello propicia para el disfrute y participación de los más pequeños. Era este un tiempo destinado desde la Antigüedad a licencias festivas, a ritos para atraer buena suerte coincidiendo con el cambio de año y a determinadas mascaradas que comportaban una inversión de las jerarquías ${ }^{42}$.

39 Bartolomé Martínez, Bernabé. «Los niños del coro en las catedrales españolas. Siglos XII-XVIII». Burgense, 1988, vol. 29, n. ${ }^{\circ}$ 1, pp. 139-193, y "La enseñanza de la música en las catedrales». Anuario de Estudios Medievales, 1991, vol. 21, pp. 607-627.

40 Los ejemplos estudiados para Toledo, recogidos en algunas referencias de las Actas Capitulares entre 1491 a 1493, apuntan a vecinos de Toledo, Villarta, Almorox, al sobrino de un racionero, al hijo de una viuda, entre otros. ACT, Actas Cap. II, fols. 15v, 26r, 48r, 54v. 24, p. 166.

41 Homet, Raquel. «Niños y adolescentes en fiestas y ceremonias». En la España Medieval, 2001, vol.

42 Ladero Quesada, Miguel Ángel. Las fiestas en la cultura medieval. Barcelona: Areté, 2004, pp. 36-42. Narbona Vizcaíno, Rafael. La ciudad y la fiesta: cultura de la representación en la sociedad medieval. Madrid: Síntesis, 2017, pp. 180-188. García Herrero, María del Carmen. «Niños y jóvenes en el ciclo festivo del invierno bajomedieval». En SABATÉ (ed.), La formació de la personalitat a l'Edat Mitjana, pp. 69-91. 
En Toledo, ese ciclo navideño se concretaba en una serie de ceremonias que concitaban un gran entusiasmo popular y en las que el protagonismo de nuestros clerizones era notable: la fiesta del obispillo, la profecía de la Sibila o el drama litúrgico del anuncio de los pastores. Aunque la fiesta que abría todos estos alborozos navideños era la del obispillo, la dejaré para el final y apuntaré primero las diversas ceremonias que se desarrollaban la noche del 24 al 25 de diciembre. Todo comenzaba con los maitines, que arrancaban a las diez de la noche, antes de lo habitual, e incluían, entre otros oficios, el canto de la Sibila. Su personaje, el de una profetisa que declama unos versículos del también profeta Isaías, estaba encarnado por un clerizón vestido con aderezos de mujer, que se desplazaba desde el sagrario al coro acompañado de otros cuatro niños: dos con antorchas abriendo el cortejo y otros dos disfrazados de ángeles con espadas en la mano. Acabado su monólogo se retiraría recibiendo aguinaldos y parabienes de todos. Su original melodía llenaría de bellos sonidos las bóvedas del templo hasta el siglo XIX, pues en Toledo pervivió esta tradición mucho más que en otros lugares, donde desapareció después de Trento. Tras los maitines se celebraba la misa de media noche o del Gallo en la que también era importante la presencia infantil, pues sus cantos y danzas disfrazados de pastores eran parte importante de la celebración. Otro tanto sucedía en los laudes, en los que se escenificaba una pieza dramática sobre la adoración de los pastores con gran protagonismo de los seises ${ }^{43}$.

Siendo la presencia de los clerizones importante en los oficios señalados, si había una fiesta especialmente vinculada a la infancia en la catedral, era la de San Nicolás o del «obispillo». Esta formaba parte de un grupo de celebraciones muy características de la Edad Media en las que se proponía una ruptura -momentánea eso sí- con el orden establecido. Son las conocidas como "fiestas de locos», en las que la inversión de papeles, el tono burlesco y la presentación de un «mundo al revés» ofrecen un atractivo punto de análisis. En ellas se respiraba un espíritu de libertad e irreverencia, que implicaba una inversión de las jerarquías oficiales y que permitía al ser humano abandonar por un corto periodo de tiempo su «rol» cotidiano y adoptar otro en tono de parodia e ironía. Un mundo tan jerarquizado como el de las catedrales se adaptaba muy bien a este tipo de celebraciones en las que lo que estaba "abajo» pasaba momentáneamente a estar "arriba» y por un tiempo el centro de las solemnidades lo ocupaban los sectores más débiles y marginados de la sociedad -niños, locos, asnos incluso- a fin de realizar una sátira de las costumbres y usos sociales habituales ${ }^{44}$.

En este caso el afectado por esta inversión de papeles era el poderoso clero catedralicio, pues durante los días de la fiesta se admitía que los protagonistas no fueran las dignidades, canónigos o racioneros sino el conjunto de clerizones y estudiantes, que cambiaban su

43 Castañeda Tordera, Isidoro. «Representaciones dramáticas en el ciclo litúrgico». En GonZÁlvez Ruiz (coord.), La Catedral Primada de Toledo, pp. 424-433; Gonzálvez Ruiz, Ramón. La Navidad en la Catedral de Toledo. Toledo: Antonio Pareja Editor, 2002; Martínez Gil, Fernando. El Corpus Christi y el ciclo festivo de la catedral de Toledo. Toledo: Almud Ediciones, 2014, pp. 65-140.

44 Heers, Jacques. Carnavales y fiestas de locos. Barcelona: Ariel, 1988; Popeanga Chelaru, Eugenia. "La desacralización del mundo medieval o el "mundo al revés"». Cuadernos del CEMYR, 1994, vol. 2, pp. 89-103; Rubio García, Luis. «La fiesta del Obispillo». En Homenaje al profesor Juan Barceló Jiménez. Murcia: Academia Alfonso X el Sabio, 1990, pp. 607-612. 
papel de subordinados y encabezaban las procesiones, iniciaban responsos y ocupaban los asientos principales en el coro. Este obispo ganaba las distribuciones como un racionero durante ese día y los veinte en que se prolongaban las chanzas y el ambiente festivo propio de este oficio. Muchas catedrales occidentales albergaron este tipo de fiesta y Toledo, desde su condición de primada, no fue ninguna excepción.

La primera referencia en la documentación catedralicia es de 1343, pero no es hasta la segunda mitad del siglo xv cuando hay descripciones precisas de cómo se concretaba. En ese sentido resulta clave un Çeremoniero antiguo de la Yglesia de Toledo, realizado por el canónigo Cristóbal Alfonso de Valladolid, fallecido en $1473^{45}$. De acuerdo con este texto, dos eran las fechas principales que la enmarcaban, ambas muy relacionadas con la infancia y la inocencia: el 6 de diciembre, festividad de San Nicolás, santo de gran difusión en Occidente y patrono de los niños al serle atribuido el milagro de salvar a tres de ellos de morir ahogados, y el día 28 de ese mismo mes, conmemoración de los Santos Inocentes.

Todo comenzaba el 6 de diciembre, día de San Nicolás, después de prima, con la disposición de dos cadalsos delante de la puerta del Perdón, uno para el cabildo y otro para los clerizones, amén de un púlpito en el que se haría efectiva la elección del «obispillo». Antes de eso uno de los clerizones, el que hacía las veces de «dottor e predicador», pronunciaba un sermón en tono burlesco, el mismo que tendrían los cánticos lanzados por este bullicioso grupo infantil. Por fin llegaba el momento de la elección, que se hacía pública de una manera un tanto llamativa, mediante un artificio similar a los que se harían en otras representaciones escénicas; este hacía descender «la paloma blanca del Spíritu Sancto», que traía en el pico "el rótulo para el que ha de ser obispo». Este era el auténtico rey de la fiesta y, como tal, era ataviado con todas las vestiduras litúrgicas propias de su condición: roquete, sobrepelliz, una capa de paño colorado, al tiempo que desde el crucero descendía un ángel por un cordel «e traele el bonete colorado de grana e pónengelo en la cabeça». Todo el cortejo se dirigía entonces en procesión al coro, donde el nuevo obispo, ante el altar de Santa María, juraba los estatutos de los clerizones y bendecía a los asistentes. Después todos asistían a misa, que el obispillo y los clerizones seguían desde las sillas altas del coro, en principio reservadas a los canónigos. Con posterioridad se ofrecía una comida en casa del obispillo y de ahí toda la comitiva procesionaba a caballo hasta el monasterio jerónimo de la Sisla, para, una vez de vuelta en Toledo, pasar por algunos monasterios femeninos.

Por fin llegaba el 28 de diciembre, conmemoración de los Santos Inocentes, en que la fiesta llegaba a su apogeo. Era ese el día en el que se producía la mayor inversión de papeles hasta el punto de encontrar a canónigos y dignidades haciendo las veces de auxiliares del cabildo, algo a lo que estaban obligados so pena de perder las distribuciones y no ser tenidos en cuenta para las mismas durante un mes. En los distintos oficios, incluida misa mayor, las dignidades actuaban como pertigueros y portadores de cirios; los canónigos hacían de perreros, incensarios y portadores del misal; los racioneros ayudaban a vestir al obispo y sostenían el libro, los cetros, los órganos y demás ornamentos necesarios. En

45 Constituciones del obispillo (1538, diciembre, 5). ACT, I.3.C1.1a, fols. 3r-5r. «C.5, De cómo se ha de çelebrar la fiesta de Sant Nycolás por los clerisones si caia en domingo». 
muchas de estas celebraciones había algunas chanzas procaces y "pullas bellacas», incluido el sermón que pronunciaba el obispo, en el que se deslizaban algunas «deshonestidades». Todo concluía con un banquete costeado en parte por el propio cabildo ${ }^{46}$ y los prelados ${ }^{47}$. Ya por la tarde, tras vísperas, acababan los fastos con una procesión a la capilla de Santiago donde se le desposeía de sus ropas litúrgicas y se terminaba con la inversión de papeles.

Las procesiones y cortejos que salían de la catedral dejan atónito a un público que disfrutaba sobremanera con esa inocentada permitida en la que se expresaba una crítica burlesca hacia la actividad de los capitulares y, al propio tiempo, una pedagogía destinada a mostrar la fragilidad de las jerarquías humanas. Su grado de aceptación entre la sociedad fue tal, que resulta difícil precisar si estamos ante una fiesta propia de la cultura popular o de la eclesiástica, ya que en ella están muy mezclados ambos niveles. Eso sí, el entusiasmo ante este mundo organizado al revés, los efectos del banquete y el tono de chanza que desde un principio presidía la fiesta desembocaban en ciertos actos grotescos, irreverencias y mofas que no siempre gustaban a las autoridades eclesiásticas. Una de las críticas más severas a las situaciones que provocaba la fiesta la realiza el arzobispo Carrillo, en el Concilio provincial de Aranda de 1473, que señala claramente a los actos deshonestos y comedias que se hacían «en la fiesta de la Natividad de Nuestro Señor Jesucristo y San Esteban, Juan y los Inocentes», es decir, todas las que estaban relacionadas con este ciclo invernal. El prelado habla incluso de turpia carmina et derisorii sermones, que impedían la celebración de los oficios divinos y en nada alentaban a la devoción del pueblo; por ello los prohíbe y castiga a quienes los permitieran con una multa y la pérdida por un mes de su ración ${ }^{48}$. Veinte años después no habrían cambiado demasiado las cosas a juzgar por el recordatorio que en 1492 ha de hacer el cabildo para que guarden las disposiciones de Carrillo, debido a que los días que iban desde San Nicolás a los Inocentes «se fasían e desían cosas desonestas de que el pueblo tomava mal exemplo» ${ }^{49}$.

Lo cierto es que se inicia una corriente de opinión contraria a este tipo de celebraciones burlescas, que lleva a poner cortapisas e incluso a prohibir la fiesta en algunas catedrales durante las primeras décadas del siglo Xvi -Sevilla, Lérida, Gerona- hasta su definitiva supresión en el concilio de Trento. En Toledo se siguió esta misma tónica y pronto empiezan a surgir debates en el seno del cabildo sobre la conveniencia o no de celebrar la fiesta. Así lo refleja una carta que en enero de 1538 escriben al arzobispo, Juan Pardo Tavera, poniéndole en antecedentes de todos los conflictos que generaba la cuestión y solicitándole un pronunciamiento sobre el tema. En la carta se recogen los diversos pareceres que los canónigos tenían sobre la cuestión: unos, los más numerosos, eran partidarios de acabar con la celebración de la misma forma que se había hecho en

46 En 1490 se destinaron 1.000 mrs para este fin. ACT, Actas Cap. II, fol. 11r (1490, noviembre, 26).

$47 \mathrm{Al}$ menos eso hizo Cisneros entre 1495-1502, otorgando 200 mrs anuales. Así lo dicen García Oro, José y Portela Silva, María José, «El gobierno toledano del Cardenal Cisneros en las cuentas». Toletana. Cuestiones de Teología e Historia, 2000, vol. 2, p. 88. Los autores entienden equivocadamente que esta cantidad es "para gratificación del obispo auxiliar, llamado obispillo de San Nicolás», y no para los gastos de la fiesta.

48 Sánchez Herrero, José. Concilios provinciales y sínodos toledanos de los siglos XIV y XV. La Laguna: Universidad, 1976, p. 295.

49 ACT, Actas Cap. II, fol. 44r (1492, diciembre, 7). 
otras iglesias, alegando que los festejos traían consigo «danças y hombres armados y otras cosas no muy honestas a la yglesia para provocar a plazer al pueblo»; por el contrario, otro sector se resistía a acabar con una "costumbre tan antigua e inmemorial», a la que se ve como un ejemplo de humildad, y, todo lo más, admitía que se reformaran aquellas prácticas que impedían que «se çelebrase el ofiçio divino con más paçificaçión y deçençia» ${ }^{50}$.

Cada una de las partes se apoyaba en sólidos argumentos canónicos y el prelado media finalmente en la polémica con una constitución fechada el 5 de diciembre de ese mismo año ${ }^{51}$. En ella se hace eco de los «excesos» que conllevaba la fiesta, de los «ávitos yndeçentyes» y de la "perturvaçión y desasosiego» que ello provocaba en el oficio divino de esos días, así como de las «travesuras y desbergüenças» de los clerizones, tanto en los oficios diurnos como en los maitines. A la vez, es consciente de que es una ceremonia que se celebra desde tiempo inmemorial «para enxemplo de la umilldad y de la ynocençia que debe aver en los prelados y otras personas eclesiásticas y seglares». Por ello, pese a que algunos solicitan que la "quite del todo", él la mantiene porque los excesos de algunos no deben afectar al conjunto ni a una costumbre tan arraigada. Eso sí, pone algunas condiciones a fin de que se celebre con mayor honestidad y moderación: prohíbe el sermón, las danzas, la bendición del obispo o salir a caballo por las calles. Además, impone a quienes lo incumplieran las correspondientes penas, en concreto la pérdida de dos meses de ingresos (enero y febrero), pues no se les permitiría entrar en el templo.

Estas y otras medidas fueron desvirtuando la fiesta y privándola de algunos de sus elementos más significativos, hasta su total abolición que llegó en el Concilio provincial toledano de 1565 , primero que se celebró en la provincia eclesiástica después de las resoluciones de Trento. En la citada convocatoria, además de otros muchos temas, se tomó en consideración «el torpe abuso de la elección fingida y pueril de obispillos», así como la "gran ignominia del orden eclesiástico» que conllevaban estas celebraciones de los Inocentes; de ahí que se prohiban, so pena de ser suspendido de su oficio por seis meses aquel que lo consintiese y penado con una multa pecuniaria pagadera a la fábrica catedralicia ${ }^{52}$.

De esta forma se acaba con la fiesta más atractiva por su innovación y ruptura del orden establecido de cuantas se celebraban en la catedral primada. Ahora bien, ese carácter transgresor no va más allá de unos días al año, pasados los cuales la catedral y su cabildo volvían a recuperar, con más fuerza si cabe, el mando de la situación y la autoridad sobre los jóvenes clerizones. Por eso los responsables catedralicios consentían la celebración de estas «travesuras» en las que canónigos y dignidades eran el objeto de la chanza y que, si sobrepasaban ciertos límites, podían representar algún peligro. El cabildo se avenía a ser el objeto de la sátira, sabedor de que, por mucha parodia que se hiciese, el control de la situación era suyo y la duración de la libertad efímera. Heers pone el dedo en la llaga al afirmar que, aunque de modo burlesco, la fiesta del obispillo

50 ACT, I.6.C.1.13. (1538, enero, Toledo)

51 Se localiza en la Biblioteca del Palacio Real y ha sido publicado por Esteve Roldán, Mecenazgo, Reforma y música en la Catedral de Toledo.

52 Un estudio sobre el concilio, que incluye además la publicación de sus actas, en Fernández CollaDo, Ángel. El Concilio Provincial Toledano de 1565. Roma: Instituto Español de Historia Eclesiástica, 1995. 
deja constancia en la ciudad que la celebra de la pujanza del grupo catedralicio, del que también forman parte estos servidores o protegidos que por un día tocan la gloria. Esta es para el autor la clave que explica el interés que incluso los canónigos más ricos y eruditos tenían en esta fiesta y el porqué la toleraban a pesar de las irreverencias que se lanzaban contra ellos ${ }^{53}$. Algunos autores, no obstante, piensan que el interés del cabildo al consentir la fiesta no era solo el de reforzar su poder. También miraba por la formación de los clerizones y de ahí que dé a la fiesta un contenido didáctico, ya que el sermón que tenían que pronunciar y el resto de sus actuaciones en el coro eran una forma de aficionar a los jóvenes al oficio sacro y de proporcionarles una suerte de «ensayo" de lo que podrían ser sus ocupaciones habituales, si decidieran seguir la carrera eclesiástica ${ }^{54}$. Lo cierto es que aquellos mozos que tomaban el papel de obispo durante las celebraciones quedaban significados en alguna forma y desde entonces, cuando se aludía a ellos, junto a su nombre aparecía la expresión «clerizón, obispo que fue de San Nicolás» ${ }^{55}$.

\section{LOS «NINNOS DE LA PIEDRA»}

No entran en el mismo nivel que los anteriores, ni por edad ni por actividad, pero hablar de la presencia infantil en la catedral toledana obliga necesariamente a prestar atención a los niños que eran abandonados en el interior del templo, en una "piedra a modo de cuna» situada frente a la capilla parroquial de San Pedro. Sobre estos pequeńos -nacidos fuera del matrimonio o de parejas que no podían atenderlos por falta de medios- recaía una situación de mendicidad, pobreza y prostitución a la que fueron sensibles los capitulares cuando deciden hacerse cargo de ellos.

La primera iniciativa de la que nos ha quedado constancia es la de uno de los miembros más destacados del cabildo, el nuncio Francisco Ortiz, que en 1483, cuando funda un hospital para enfermos mentales -el de la Visitación o los Inocentes- dispone que, además de a un número de dementes, se albergue a trece niños expósitos «que las madres desanparavan carescientes a la razón natural que los animales brutos usan con sus hijos ${ }^{56}$. El nuncio tiene bien presente el futuro que les esperaba a estos pequeños abandonados y él mismo relata cómo por la ciudad andaban muchos pidiendo limosna, circunstancia que le mueve a dar cabida a trece de ellos, número de evangélicas connotaciones, en su hospital.

No obstante, los nińos abandonados superarían esta cifra y por eso el cabildo decide tomar cartas en el asunto. Las actas del capítulo espiritual celebrado el 8 de abril de 1491 ofrecen la imagen de un cabildo preocupado por «los ninnos e ninnas que se echan en la piedra» y que acuerda que, «sy el sennor nunçio quysyere tomar algunos

53 Heers, Carnavales y fiestas de locos, pp. 170-171.

54 Rubio García, «La fiesta del Obispillo», pp. 609-610.

55 ACT, Actas Cap. I, fol. 71v. Es lo que sucedió el 6 de octubre de 1474, cuando se encomienda una lectoría al clerizón Diego de la Parra.

56 Lop Otín, El Cabildo catedralicio de Toledo en el siglo XV, pp. 371-374. 
dellos, los tome e los que no que el cabildo tenga cargo de los faser tomar e criar ${ }^{57}$. A tal efecto, la corporación proporcionaría el soporte económico necesario $-14.000 \mathrm{mrs}$ anuales de las rentas del refitor- y diputaría a un canónigo para entender en todo lo concerniente al tema ${ }^{58}$. Poco después, en noviembre del mismo año, el cabildo vota las constituciones de este oficio, que especifican claramente sus competencias, entre las que está la de llevar un libro-registro que consignara los nombres de los nińos, la fecha en que fueron recogidos y los gastos de su manutención -amas de cría, pañales, mantillas- con objeto de que su sucesor en el cargo "pueda continuar la cuenta e no aya yerro en ello». El concurso de las amas de cría era fundamental para poder atender al cuidado de los pequeños; de ahí que buena parte del presupuesto se fuera en el pago a las mismas. Estas cobraban cada mes o dos meses, según los casos, y en el momento de la paga debían llevar consigo al niño "porque no puedan faser enganno e levar el salario sy era muerto el ninno e jurar que es aquel mysmo el que le fue dado a criar». Tanta precaución del cabildo induce a pensar que los fraudes entre estas mujeres no serían extraños; de ahí que los capitulares exijan sus garantías. Por último, el canónigo encargado de estos niños debía hacerlos bautizar ${ }^{59}$.

Las iniciativas del cabildo en relación a estos niños expósitos se transformaron a finales del siglo xv, cuando el poderoso cardenal Pedro González de Mendoza legó su patrimonio para erigir una institución que se ocupase específicamente de dar respuesta a este problema. Se trata del Hospital de Santa Cruz, que pretendía, además, concentrar los numerosos establecimientos asistenciales de la ciudad, muchos de ellos con rentas y dimensiones muy modestas. Así lo dispuso en su testamento, otorgado en Guadalajara en junio de 1494, pocos meses antes de su muerte. La dimensión sanitaria de la institución se perdería a lo largo del siglo XVI, no así la atención a los expósitos, que se mantendría hasta el siglo xix. Las obras comenzaron en 1504-1505 y diez años después ya pudieron los niños ocupar el edificio, si bien continuaron los trabajos algún tiempo más. De lo que no hay duda es de que la fundación mendociana alcanzó pronto un gran éxito y cada vez acogió un mayor número de niños. En 1517 se ordenó incluso que no superasen los 200, pero fue tal el aumento que las rentas se hicieron insuficientes. La fundación fue importante para el cabildo, pues desde el principio el cardenal, sabedor de que probablemente no viera realizado su proyecto a causa de su edad, decidió comprometer a la corporación a la que hizo patrona y protectora del centro asistencial ${ }^{60}$.

En tanto este se ponía en marcha y tenía a punto sus instalaciones, el cabildo siguió acogiendo a los niños de forma directa, tarea para la que recibió la ayuda de Cisneros, que en 1496, nada más hacerse cargo de la sede, otorgó 102.000 mrs "para criar a los ninnos que se echan a la puerta de dicha nuestra santa Yglesia de Toledo»" ${ }^{61}$.

57 ACT, Actas Cap. II, fol. 16v.

58 Los canónigos elegidos debían aceptar obligatoriamente el cargo, so pena de perder un ańo de caridades y distribuciones por su prebenda. A cambio se veían recompensados con un salario anual de $3.000 \mathrm{mrs}$.

59 ACT, Actas Cap. II, fol. 25v.

60 Lop Otín, María José y Rodríguez González, Alfredo. «La catedral y las obras sociales». En Gonzálvez Ruiz (coord.), La Catedral Primada de Toledo, pp. 449-473.

61 ACT, V.3.B.1.1. 
DE CATEDRALES, ESCUELAS Y NIÑOS: EL EJEMPLO DEL TOLEDO BAJOMEDIEVAL MARÍA JOSÉ LOP OTÍN

\section{Comentario final}

Espero que tras la lectura de estas líneas haya quedado probada esa presencia de voces infantiles en la catedral primada, presencia que no sería excepcional, sino más bien habitual y reiterada año tras año, merced a la llegada de nuevos efectivos para cubrir alguna de las plazas de clerizones que quedaran vacantes. Los distintos espacios del templo se «humanizarían» de algún modo con estos nińos y adolescentes, que por su edad no siempre se ajustarían a los rígidos moldes de la normativa capitular y proporcionarían cierta frescura al día a día catedralicio. Ya sea en su faceta de estudiantes, de auxiliares del coro, de cantores o de actores en las representaciones litúrgicas, darían, sin duda, un toque original, cuando no burlesco y divertido a su paso por el templo. Este, además, estaba estrechamente vigilado por los responsables del cabildo, maestrescuela y chantre en especial, sabedores como eran de que la preparación que estos jóvenes obtuvieran sería decisiva para facilitarles una prometedora carrera, dentro o fuera de la Iglesia.

Podría haber completado el texto con la referencia a los libros custodiados en la Biblioteca Capitular que nos dan información sobre el tema de la infancia. Es lo que hicieron para el caso francés dos historiadoras y arqueólogas francesas, que, partiendo de un exhaustivo análisis de los manuscritos miniados conservados en la Biblioteca $\mathrm{Na}$ cional de Francia, supieron retratar muchos aspectos de la vida cotidiana y del entorno material de la infancia medieval ${ }^{62}$. Queda, pues, pendiente esa segunda mirada, que aquí no he podido explorar, pero que, dados los ricos fondos de la biblioteca toledana, no hay que descartar pueda proporcionarnos interesantes frutos.

\section{REFERENCIAS BIBLIOGRÁFICAS}

Alexandre-Bidon, Danièle y Closson, Monique. La infancia a la sombra de las catedrales. Zaragoza, Prensas Universitarias, 2008.

Bartolomé Martínez, Bernabé, «Escuelas de Gramática». En Diccionario de Historia Eclesiástica de España. Madrid: Consejo Superior de Investigaciones Científicas, 1987, Supl. I, pp. 290-291.

Bartolomé Martínez, Bernabé. "La enseñanza de la música en las catedrales». Anuario de Estudios Medievales, 1991, vol. 21, pp. 607-627.

Bartolomé Martínez, Bernabé, «Los niños del coro en las catedrales espańolas. Siglos XII-XVIII». Burgense, 1988, vol. 29, n. ${ }^{\circ}$ 1, pp. 139-193.

Canabal Rodríguez, Laura. «Conversos toledanos en un espacio de poder, la catedral primada. Don Francisco Álvarez de Toledo, canónigo y mecenas (ss. xv y xvI)». Espacio, Tiempo y Forma. Serie IV, Historia Moderna, 2011, vol. 24, pp. 13-32.

CASTAÑEDa ToRDera, Isidoro. «Representaciones dramáticas en el ciclo litúrgico». En GonZálvez Ruiz, Ramón (coord.). La Catedral Primada de Toledo. Dieciocho siglos de historia. Burgos: Promecal Publicaciones, 2010, pp. 424-433.

Esteve Roldán, Eva. Mecenazgo, Reforma y música en la Catedral de Toledo (1523-1545). Tesis doctoral leída en la Universidad Complutense. Madrid, 2015.

62 Alexandre-Bidon, Danièle y Closson, Monique. La infancia a la sombra de las catedrales. Zaragoza, Prensas Universitarias, 2008. 
DE CATEDRALES, ESCUELAS Y NIÑOS: EL EJEMPLO DEL TOLEDO BAJOMEDIEVAL MARÍA JOSÉ LOP OTÍN

Fernández Collado, Ángel. El Concilio Provincial Toledano de 1565. Roma: Instituto Español de Historia Eclesiástica, 1995.

García de Cortázar, José Ángel. «El ritmo del individuo: del nacimiento a la muerte». En Historia de España Menéndez Pidal. Madrid: Espasa-Calpe, 1994, vol. XVI.

García Herrero, María del Carmen. «Elementos para una historia de la infancia y la juventud a fines de la Edad Media». En La vida cotidiana en la Edad Media. Logroño: Instituto de Estudios Riojanos, 2011, pp. 223-252.

García Herrero, María del Carmen. "Las etapas de la vida». Medievalismo, 2004, vol. 13-14, pp. 29-48.

García Herrero, María del Carmen. «Niños y jóvenes en el ciclo festivo del invierno bajomedieval». En Sabaté, Flocel (ed.). La formació de la personalitat a l'Edat Mitjana. Lleida: Pagès editors, 2016, pp. 69-91.

García Oro, José y Portela Silva, María José, «El gobierno toledano del Cardenal Cisneros en las cuentas». Toletana. Cuestiones de Teología e Historia, 2000, vol. 2, pp. 77-144.

García y García, Antonio (dir.). Synodicon Hispanum. X. Cuenca y Toledo. Madrid: Biblioteca de Autores Cristianos, 2011.

Gómez Sánchez, Florentino. «El Colegio de Santa Catalina y la Universidad de Toledo». Iluminar, 1988, vol. I, pp. 61-78.

Gonzálvez Ruiz, Ramón. «La Escuela catedralicia». En Gonzálvez Ruiz, Ramón (coord.). La Catedral Primada de Toledo. Dieciocho siglos de historia. Burgos: Promecal Publicaciones, 2010, pp. 518-525.

Gonzálvez Ruiz, Ramón. La Navidad en la Catedral de Toledo. Toledo: Antonio Pareja Editor, 2002.

Guijarro González, Susana. «El saber de los claustros: las escuelas monásticas y catedralicias en la Edad Media». Arbor: ciencia, pensamiento y cultura, 2008, vol. 731, pp. 443-455.

Guijarro González, Susana. «Las escuelas y la formación del clero de las catedrales en las diócesis castellano-leonesas». En La Enseñanza en la Edad Media. Logroño: Instituto de Estudios Riojanos, 2000, pp. 61-96.

Guijarro González, Susana. Maestros, escuelas y libros: el universo cultural de las catedrales en la Castilla medieval. Madrid: Dykinson, 2004.

Heers, Jacques. Carnavales y fiestas de locos. Barcelona: Ariel, 1988.

Historia de la acción educadora de la Iglesia en España. I. Edades Antigua, Media y Moderna. Madrid: Biblioteca de Autores Cristianos, 1995.

Номет, Raquel. «Niños y adolescentes en fiestas y ceremonias». En la España Medieval, 2001, vol. 24, p. 145-169.

Ladero Quesada, Miguel Ángel. Las fiestas en la cultura medieval. Barcelona: Areté, 2004.

Le Goff, Jacques. La civilización del Occidente medieval. Barcelona: Paidos, 1999.

Lop OTín, María José. «El esplendor litúrgico de la catedral primada de Toledo durante la Edad Media». Medievalia, 2014, vol. 17, pp. 185-213.

Lop Otín, María José. «La Catedral de Toledo, ente generador de cultura a fines de la Edad Media». En Boucheron, Patrick y Ruiz Gómez, Francisco (coords.). Modelos culturales y normas sociales al final de la Edad Media. Cuenca: Casa de Velázquez-Universidad de Castilla-La Mancha, 2009, pp. 357-385.

Lop Otín, María José. El Cabildo catedralicio de Toledo en el siglo XV: Aspectos institucionales y sociológicos. Madrid: Fundación Ramón Areces, 2003.

Lop Otín, María José y Rodríguez GonzÁLez, Alfredo. «La catedral y las obras sociales». En Gonzálvez Ruiz, Ramón (coord.). La Catedral Primada de Toledo. Dieciocho siglos de historia. Burgos: Promecal Publicaciones, 2010, pp. 449-473. 
López Gómez, Juan Estanislao. El Colegio de Infantes de Toledo en la Edad Moderna, 1552-1808. Toledo: Grupo Díaz Redondo, 2007.

Lorente Toledo, Luis. La Real y Pontificia Universidad de Toledo. Siglos XVI-XIX. Toledo: Universidad de Castilla-La Mancha, 1999.

Martín Prieto, Pablo. La cultura en el Occidente medieval. Una síntesis histórica. Madrid: La Ergástula, 2013.

Martínez Gil, Fernando. El Corpus Christi y el ciclo festivo de la catedral de Toledo. Toledo: Almud Ediciones, 2014.

Narbona Vizcaíno, Rafael. La ciudad y la fiesta: cultura de la representación en la sociedad medieval. Madrid: Síntesis, 2017.

Noone, Michael. «La música medieval y renacentista». En Gonzálvez Ruiz, Ramón (coord.). La Catedral Primada de Toledo. Dieciocho siglos de historia. Burgos: Promecal Publicaciones, 2010, pp. 332-341.

Paul, Jacques. Historia intelectual del Occidente medieval. Madrid: Cátedra, 2003.

Popeanga Chelaru, Eugenia. "La desacralización del mundo medieval o el "mundo al revés"». Cuadernos del CEMYR, 1994, vol. 2, pp. 89-103.

Reynaud, François. La polyphonie tolédane et son milieu. Des premiers témoignages aux environs de 1600. Paris-Turnhout: Brepols, 1996.

Reynaud, François. Les enfants de choeur de Tolède à la Renaissance. Les clerizones de la cathédrale et le Colegio de los Infantes. Turnhout: Brepols, 2002.

Rubio García, Luis. "La fiesta del Obispillo». En Homenaje al profesor Juan Barceló Jiménez. Murcia: Academia Alfonso X el Sabio, 1990, pp. 607-612.

Sabaté, Flocel. «La formació de la personalitat a l'Edat Mitjana». En SabatÉ, Flocel (ed.). La formació de la personalitat a l'Edat Mitjana. Lleida: Pagès editors, 2016, pp. 9-22.

Sánchez Herrero, José. Concilios provinciales y sinodos toledanos de los siglos XIV y XV. La Laguna: Universidad, 1976.

Sánchez Prieto, Ana Belén. «Dónde aprender a leer y escribir en el año mil». Anuario de Estudios Medievales, 2010, vol. 40, n. ${ }^{\circ}$ 1, pp. 3-34.

Vizuete Mendoza, José Carlos. «La Universidad y los Colegios de Santa Catalina y San Bernardino». En Gonzálvez Ruiz, Ramón (coord.). La Catedral Primada de Toledo. Dieciocho siglos de historia. Burgos: Promecal Publicaciones, 2010, pp. 534-541.

Vizuete Mendoza, José Carlos. «Universidad de Toledo: historiografía, fuentes documentales y líneas de investigación». En Universidades hispánicas: modelos territoriales en la Edad Moderna. Salamanca: Universidad de Salamanca, 2007, vol. 2, pp. 65-106.

Vizuete Mendoza, José Carlos. Los antiguos colegios-universidad de Toledo y Almagro. Cuenca: Universidad de Castilla-La Mancha, 2010. 